\title{
Algorithms and Applications in Grass Growth Monitoring
}

\author{
Jun Liu, ${ }^{1,2}$ Xi Yang, ${ }^{2}$ Hao Long Liu, ${ }^{1}$ and Zhi Qiao ${ }^{3}$ \\ ${ }^{1}$ Institute of Geographic Sciences and Natural Resources Research, Chinese Academy of Sciences, All Datun Road, \\ Chaoyang District, Beijing 100101, China \\ ${ }^{2}$ College of Geography and Tourism, Chongqing Normal University, No. 12 Tianchen Road, Shapingba District, \\ Chongqing 400047, China \\ ${ }^{3}$ State Key Laboratory of Water Environment Simulation, School of Environment, Beijing Normal University, \\ No. 19 Xinjiekouwai Street, Beijing 100875, China
}

Correspondence should be addressed to Zhi Qiao; george@mail.bnu.edu.cn

Received 25 February 2013; Accepted 29 March 2013

Academic Editor: Craig Caulfield

Copyright (C) 2013 Jun Liu et al. This is an open access article distributed under the Creative Commons Attribution License, which permits unrestricted use, distribution, and reproduction in any medium, provided the original work is properly cited.

\begin{abstract}
Monitoring vegetation phonology using satellite data has been an area of growing research interest in recent decades. Validation is an essential issue in land surface phenology study at large scale. In this paper, double logistic function-fitting algorithm was used to retrieve phenophases for grassland in North China from a consistently processed Moderate Resolution Spectrodiometer (MODIS) dataset. Then, the accuracy of the satellite-based estimates was assessed using field phenology observations. Results show that the method is valid to identify vegetation phenology with good success. The phenophases derived from satellite and observed on ground are generally similar. Greenup onset dates identified by Normalized Difference Vegetation Index (NDVI) and in situ observed dates showed general agreement. There is an excellent agreement between the dates of maturity onset determined by MODIS and the field observations. The satellite-derived length of vegetation growing season is generally consistent with the surface observation.
\end{abstract}

\section{Introduction}

Vegetation phenology is the study of periodic plant life cycle events, such as bud burst, leaf out, flower bloom, and leaf fall, and how these are influenced by seasonal and interannual changes in environment [1]. Because small fluctuations of climate can make a big difference in the timing of the vegetation phenological events, plant phenology is widely accepted as a robust indicator of the response of terrestrial ecosystems to climate change $[2,3]$. Variations in the timing of vegetation phenophases are key components to identify and evaluate the effects of climatic change on terrestrial ecosystems $[4,5]$. Plant phonological monitoring has been an area of growing research interest in recent decades.

Plant phenophases have been monitored by field observations for thousands of years [6,7]. Long-term records of species-level phenophases are useful in monitoring local climatic changes $[8,9]$. However, field phenological observations are difficult to extrapolate to large spatial scale and working intensive.
Satellite-based remotely sensed data provides the potential to scale from species-level observations to regional shifts of phenological patterns [10]. More than 150 vegetation indices (VIs) have been produced from satellite data to describe the information of vegetation. Each index is designed to accentuate a particular vegetation property. For instance, Normalized Difference Vegetation Index (NDVI) derived from reflectance data collected by the Moderate Resolution Spectroradiometers (MODIS) on Terra and Aqua provides an indication of the canopy greenness of vegetation communities. NDVI has been proved to be valid for retrieving land surface phenology [5]. A generalized VI temporal profile is theoretically smooth and continuous. However, due to the influences of the noise in the satellite data including the cloud cover, atmospheric effects, bidirectional effects, and snow cover, the time-series VI data are always with remarkable fluctuations [11].

A variety of methods are used to reduce noise in NDVI data and to reconstruct high-quality time-series VI data, for 


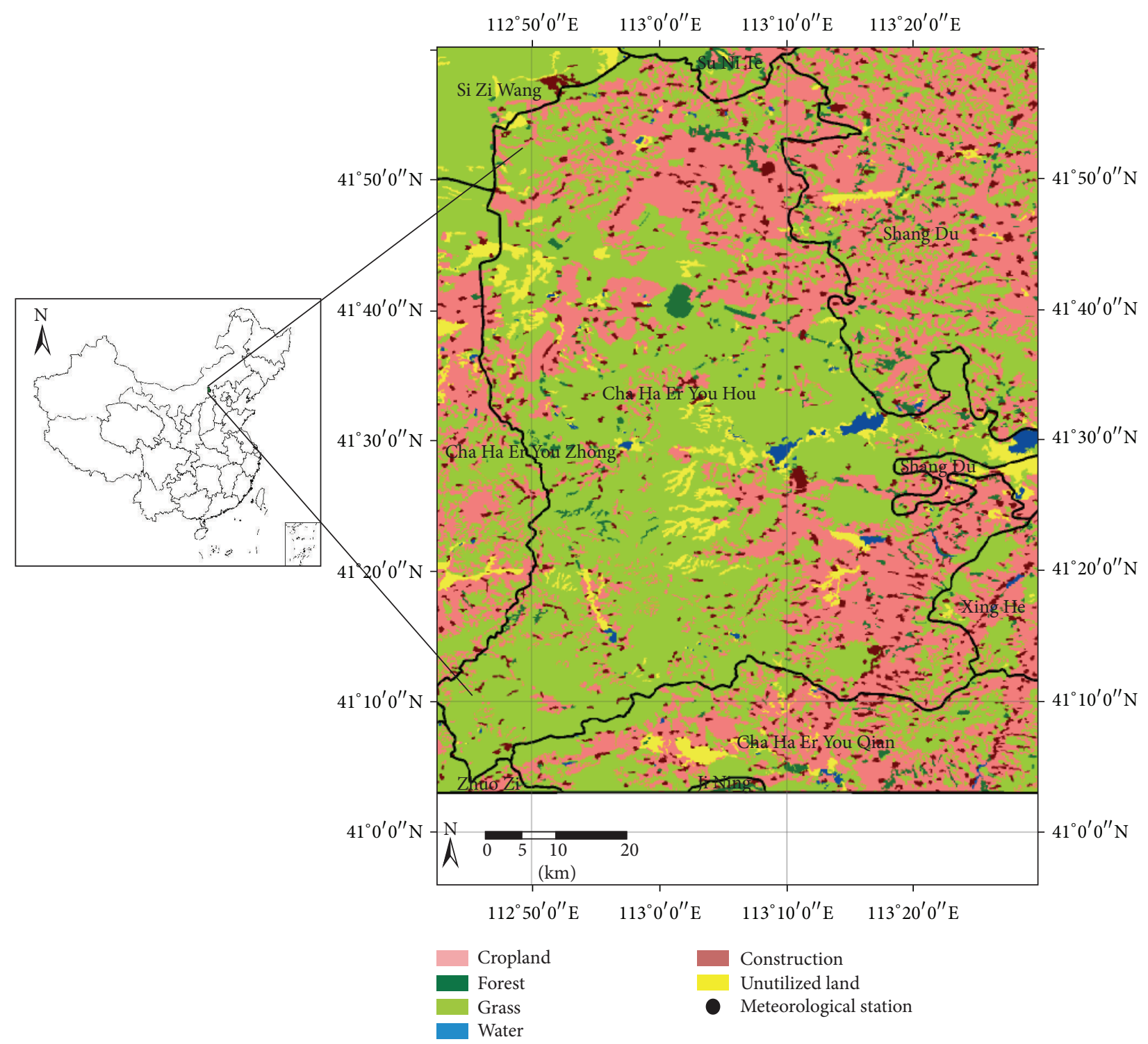

Figure 1: The location of study area.

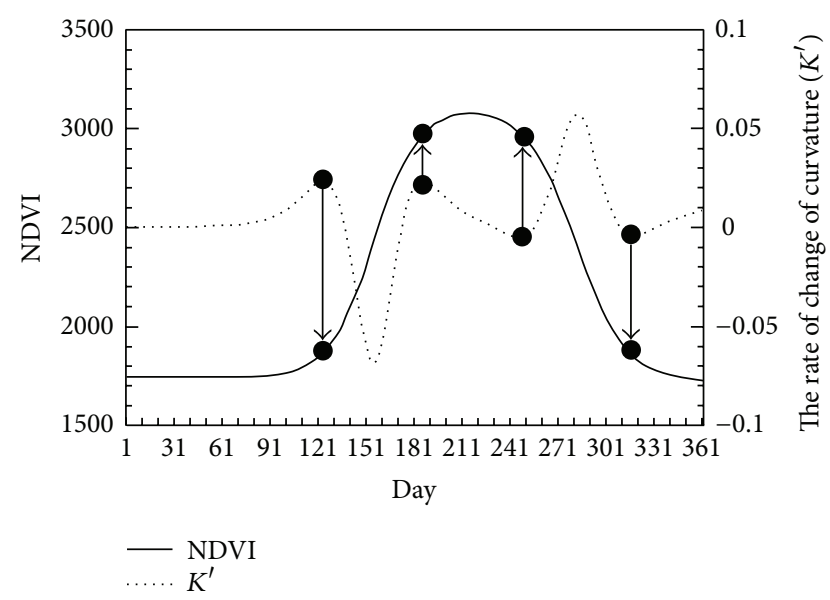

FIGURE 2: The reconstructed MOD13A2-NDVI time series and the rate of change of its curvature. example, the asymmetric Gaussian function fitting, SavitzkyGolay filters, Fourier harmonic analysis, and piecewise logistic functions. After an empirically based comparison of different methods, Jennifer recommended the double logistic function-fitting algorithm due to robustness, scientific basis, and general applicability and some other desirable properties [12]. Based on the smoothed temporal VI data, Zhang et al. identified the phenological transition dates by the derivative of the curvature of the function [13].

However, it is often ambiguous what the satelliteretrieved phenological estimates actually track. For instance, the greatest temporal increase in the NDVI is due to snow melt rather than "start of the season" (SOS) $[14,15]$. As a result, it is necessary to compare the satellite-measured land surface phenology with data observed at ground level. However, to date, measures of land surface phenology usually compare poorly with in situ observed phenology [16]. Therefore, researchers do not comprehensively understand how the 


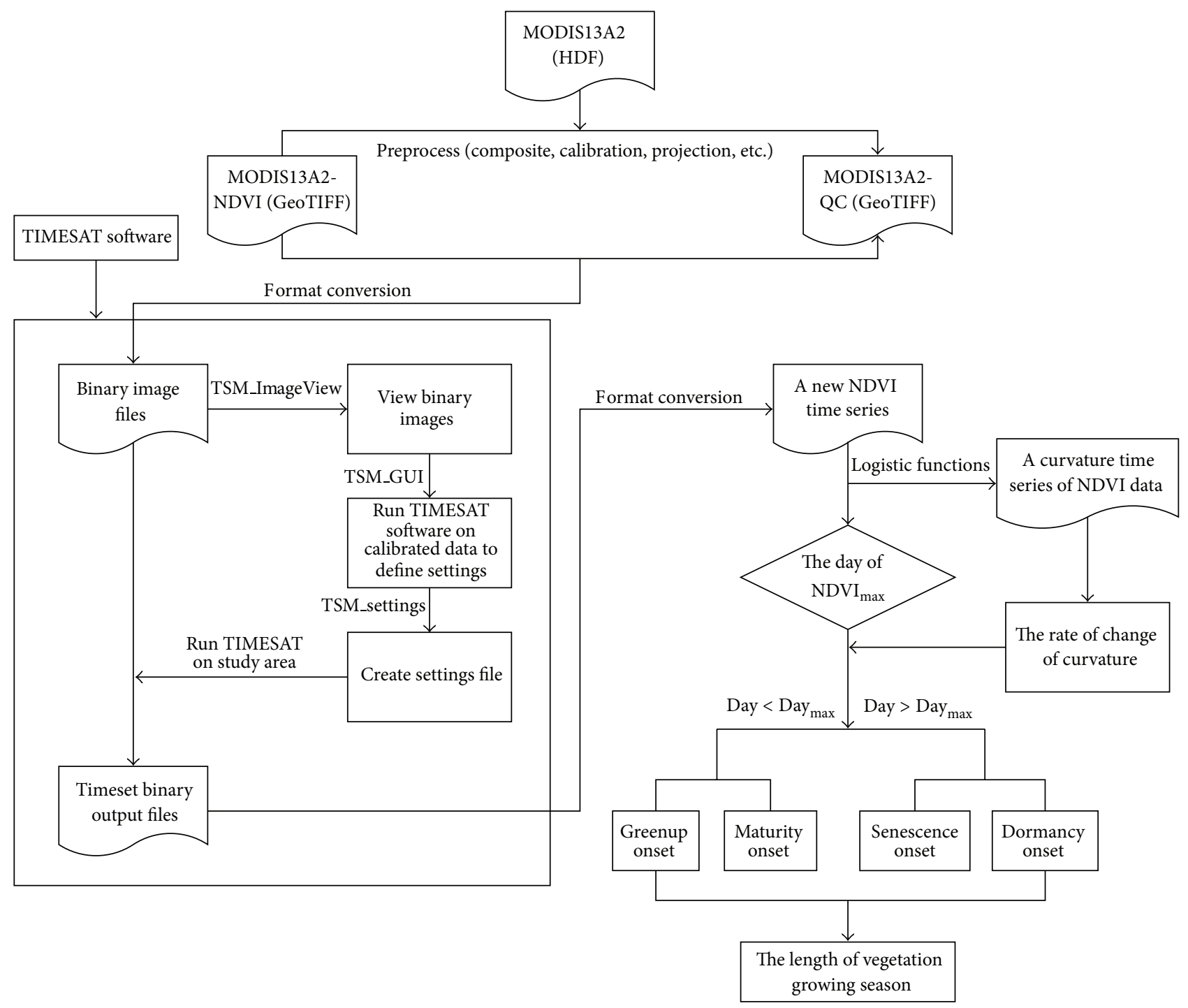

FIGURE 3: Flowchart of grassland growth monitoring process.

myriad definitions and methods are related to ground-based phenology. A primary hurdle is the incompatibility of spatial scales at which two types of observations are commonly obtained, in addition to different characteristic of the data. Such limitations have greatly impeded progress in the further application of time-series VI data.

Here, the double logistic function-fitting algorithm was used to retrieve phenophases for grassland in North China using a consistently processed MODIS dataset. Then, assessment of phenological dates was conducted using field observation phenology.

\section{Study Area}

The study was conducted on Leymus chinensis grassland in Inner Mongolia, one of the most representative grassland regions of China. Because the phenophases of Leymus chinensis are easily detectable from both field observations and remotely sensed data, it is well suited for phenological study based on remote data. Chahar Right Back Banner, the study area, is located in latitude $41^{\circ} 27^{\prime} \mathrm{N}$ and longitude $113^{\circ} 11^{\prime} \mathrm{E}$. The area is characterized by a north temperate continental monsoon climate with average annual precipitation of $325.7 \mathrm{~mm}$, average annual temperature of $4.17^{\circ} \mathrm{C}$, and mean annual aridity index of 22.99. Grassland (mainly Leymus chinensis) is the dominant vegetation (Figure 1).

\section{Material and Methodology}

\subsection{Material}

3.1.1. MODIS Data. For this study, MOD13 A2 8-day NDVI and NDVI quality assurance products from Terra's Moderate Resolution Imaging Spectroradiometer (MODIS) were used. The dataset covered one-year time series, from January 1, 2007 to December 31, 2007 and included 46 images. The MODIS data have a spatial resolution of $1 \mathrm{~km}$ at nadir, which is well suited to monitor seasonal vegetation dynamics at the 


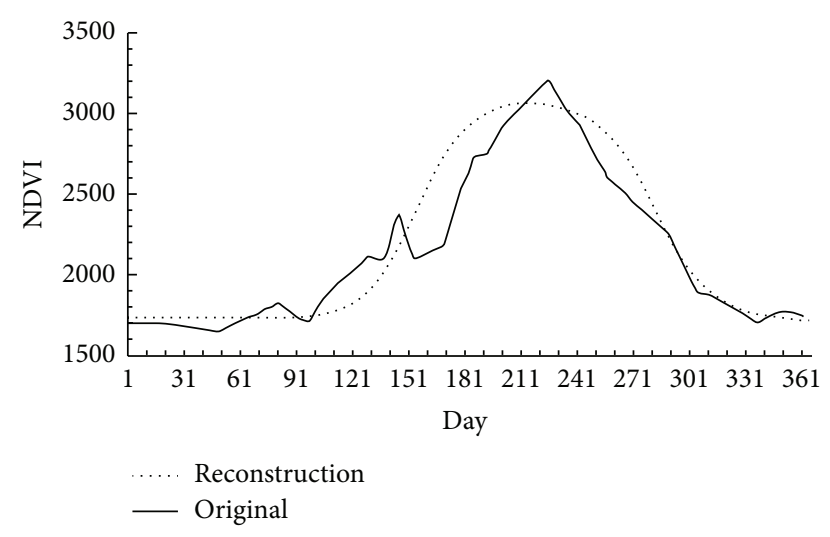

FIgURE 4: Comparison of original and reconstructed (doublelogistic functions) MOD13A2-NDVI time series.

scale of the landscape. These data were acquired from the US Geological Survey.

The NDVI is calculated from these individual measurements as follows:

$$
\mathrm{NDVI}=\frac{(\mathrm{NIR}-\mathrm{VIS})}{(\mathrm{NIR}+\mathrm{VIS})}
$$

where VIS and NIR stand for the spectral reflectance measurements acquired in the visible (red) and near-infrared regions, respectively.

3.1.2. Field-Observed Data. Ground-observed grassland phenophases were obtained from Chen and Li [17]. The observations of the different phases of Leymus chinensis are carried at Chahar Right Back Banner stations of Inner Mongolia. The observation criterion of the grassland has been developed by China Meteorological Administration.

3.2. Methodology. The selected VI values were fitted with algorithm presented in Zhang et al. [13, 18] for reconstructing smoothing timeseries curves. This algorithm characterizes vegetation growth cycles using four transition dates derived from time series of MODIS VI data: (1) greenup, the date of onset of photosynthetic activity; (2) maturity, the date at which plant green leaf area is at maximum; (3) senescence, the date at which photosynthetic activity and green leaf area begin to rapidly decrease; (4) dormancy, the date at which physiological activity becomes near zero.

The annual change in satellite-derived VI data for a single growth or senescence cycle can be modeled using

$$
y(t)=\frac{c}{1+e^{a+b t}}+d,
$$

where $t$ is time in days, $y(t)$ is the NDVI value at time $t, a$ and $b$ are fitting parameters, $c+d$ is the maximum NDVI value, and $d$ is the initial background NDVI value. The fitting parameters $a$ and $b$ were determined using least-square fitting.

The rate of the change in the curvature of the fitted logistic models is used to determine the four key transition dates (Figure 2).
A series of preprocessing steps were performed to smooth MODIS NDVI data products using TIMESAT software to identify the single growth and senescence cycle. The objective is to eliminate the abnormal value, that is, cloud and snow. Then, the VI data could be fit to logistic functions described by (2).

Zhang et al. [13] define the onset as the date when the second derivative gets from positive to negative values. The onset of four transition dates corresponds to the times at which the second derivative gets from positive to negative values. These transitions dates indicate when one phenological phase transitions from one approximately linear stage to another. The curvature $K$ for (1) at time $t$ can be computed by

$$
K=\frac{d_{a}}{d_{s}}=-\frac{b^{2} c z(1-z)(1+z)^{3}}{\left[(1+z)^{4}+(b c z)^{2}\right]^{3 / 2}},
$$

where $z=e^{a+b t}, a$ is the angle of the unit tangent vector at time $t$ along a differentiable curve, and $s$ is the unit length of the curve. The rate of change of curvature $K^{\prime}$ can be computed by

$$
\begin{gathered}
K^{\prime}=b^{3} c z\left\{\frac{3 z(1-z)(1+z)^{3}\left[2(1+z)^{3}+b^{2} c^{2} z\right]}{\left[(1+z)^{4}+(b c z)^{2}\right]^{5 / 2}}\right. \\
\left.-\frac{(1+z)^{2}\left(1+2 z-5 z^{2}\right)}{\left[(1+z)^{4}+(b c z)^{2}\right]^{3 / 2}}\right\} .
\end{gathered}
$$

The detailed flowchart of grassland growth monitoring process is illustrated in Figure 3. We first made a preprocess for the MOD13 A2 dataset taking MODIS Reprojection Tool (MRT) software as a platform. In order to eliminate the effect of cloud and snow, we smooth the dataset using TIMESAT software. For the corrected dataset, we simulated the phenophases for grassland through Arc Macro Language (AML) programming in accordance with the above algorithm.

\section{Results}

4.1. The Effect of Data Smoothing. The final smoothed curve was produced from the double logistic model. Figure 4 shows the effect of data smoothing on the time series for a grassland pixel. The reconstructed NDVI time series is smoother and the noise resulting from the atmospheric conditions is considered as outliers and removed. The new smooth and continuous time series fit to natural rules of grassland growth.

4.2. Phenophases of Grassland. The phenological pattern of grassland of Inner Mogolia during a single growth cycle is realistically identified using the method described in Section 3. Figures 5(a) to 5(e) present ecologically and geographically coherent patterns that are consistent with known phenological behavior in this area.

Greenup onset begins at the early April (124 day-of-year) in the station. Note that south areas exhibit earlier greenup. 


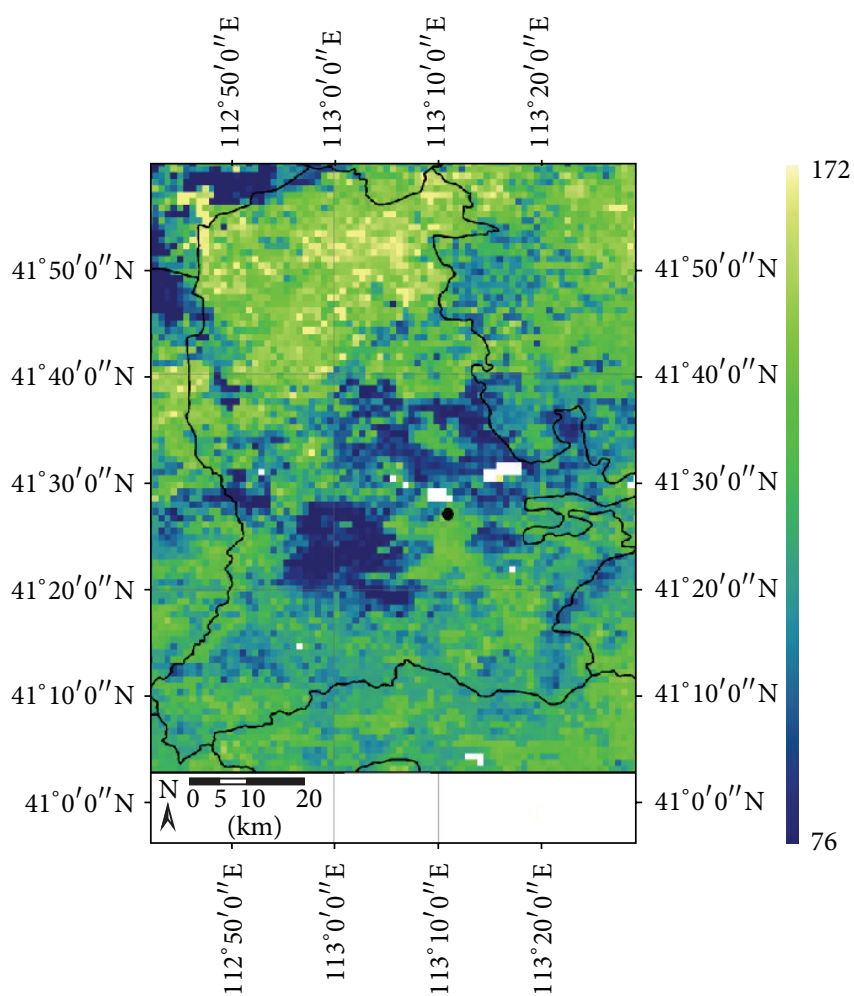

- Meteorological station

(a)

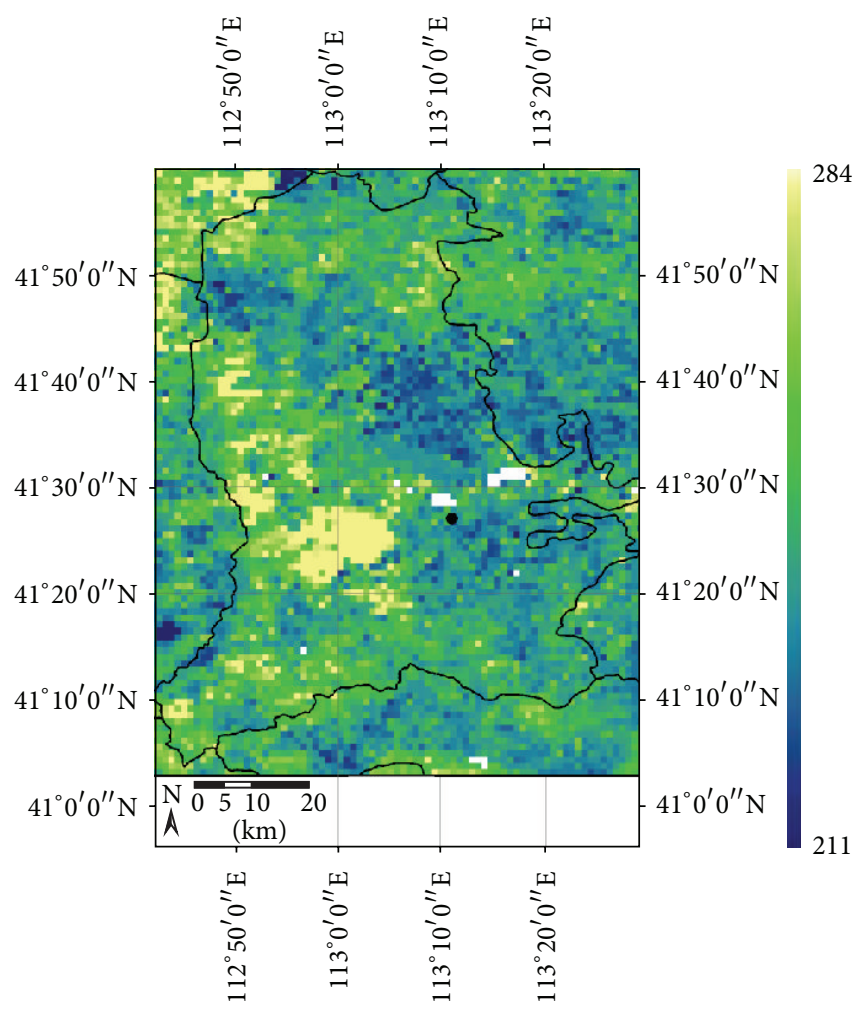

- Meteorological station

(c)

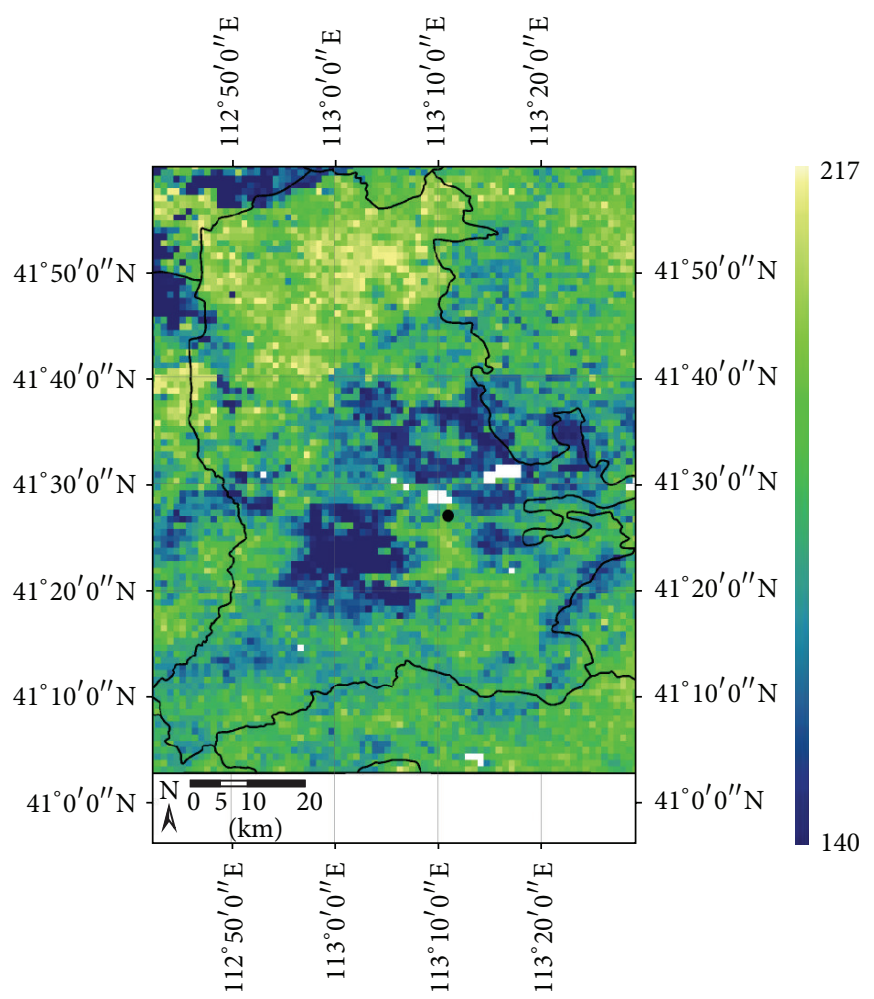

- Meteorological station

(b)

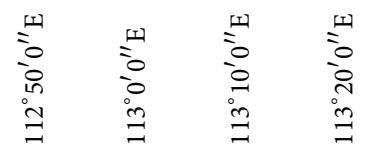

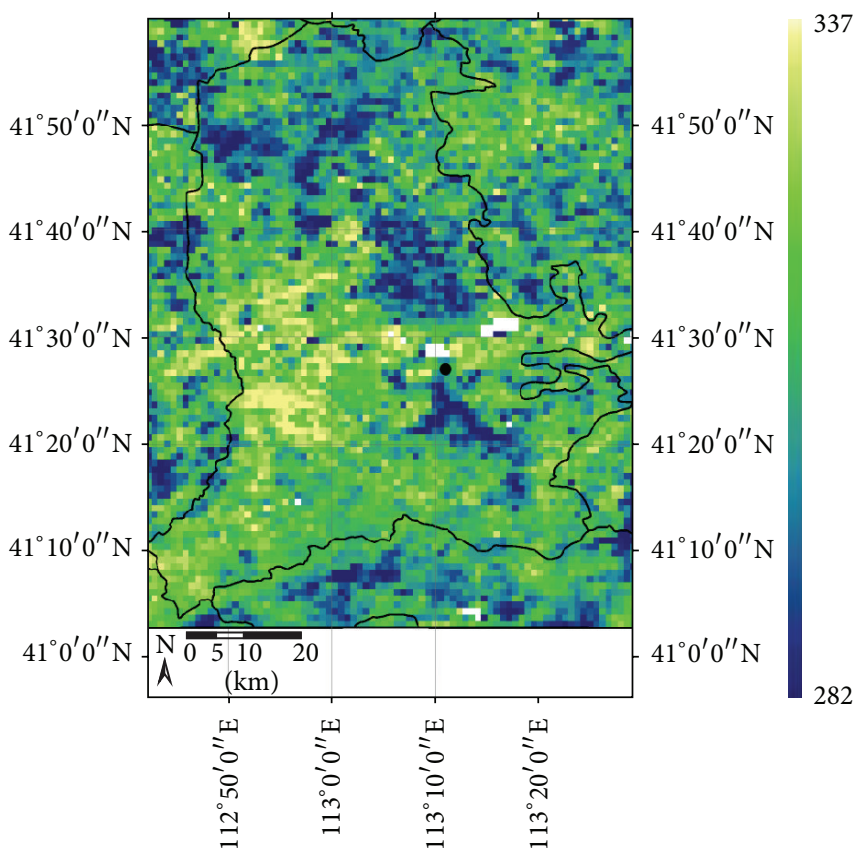

- Meteorological station

(d)

Figure 5: Continued. 


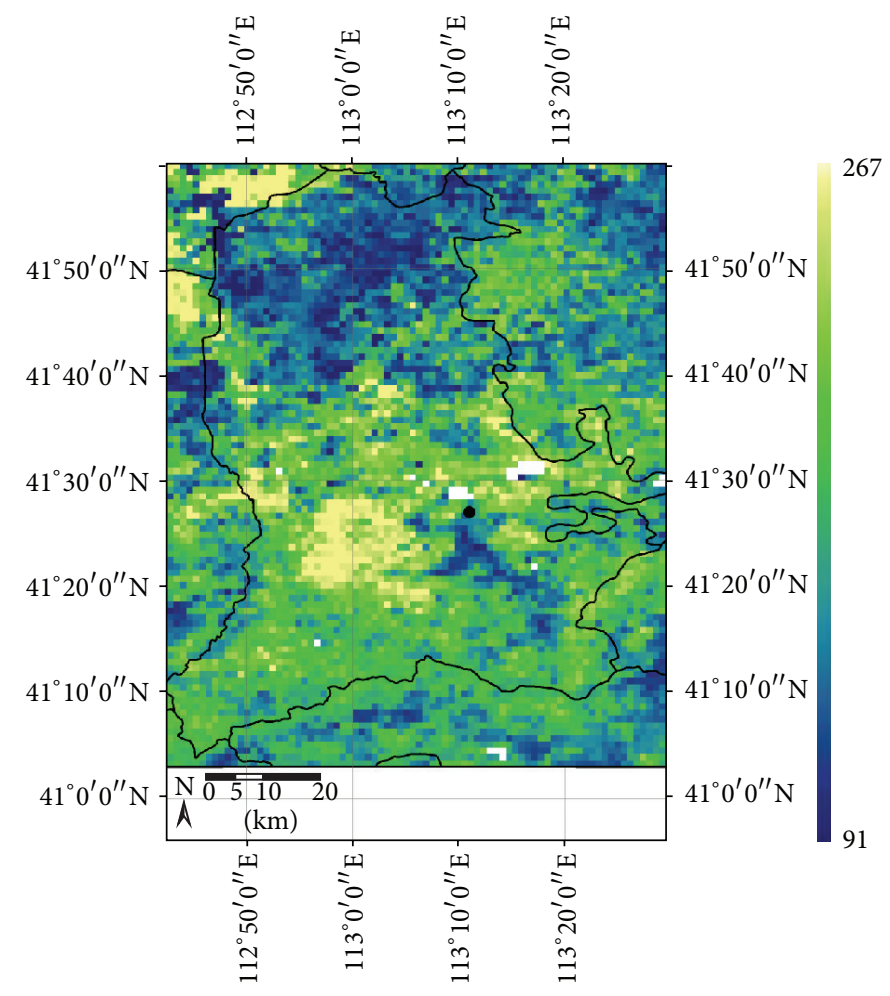

- Meteorological station

(e)

FIGURE 5: (a) greenup onset, (b) maturity onset, (c) senescence onset, (d) dormancy onset, and (e) the length of vegetation growing season.

In most regions, about 62 days are required from greenup to reach the mature phase, with relatively late mature in more northern regions. Senescence occurs at the beginning of August (247 day-of-year) without strong spatial trend. Dormancy onset begins at the end of October (318 day-ofyear). The length of the growing season is about 190 days.

4.3. Comparison with Field Observation. Table 1 presents the field-observed dates versus phenological transition dates derived from MODIS NDVI. In situ phenology observations are collected from Chen and Li [17]. Greenup onset dates identified by NDVI and in situ observed dates showed general agreement. There is an excellent agreement between the dates of maturity onset determined by MODIS and the field observations. However, values corresponding to the satellite onset estimate of senescence and dormancy date lag fieldobserved values by about $15-35$ days. The satellite-derived length of vegetation growing season is generally consistent with the surface observation.

\section{Conclusion and Discussion}

This paper presents a valid methodology to identify grassland phenophases using remote sensing data. The double logistic model has been demonstrated as a flexible, repeatable, and realistic way to reconstruct time series. The phenophases
TABLE 1: The phenophases derived from MODIS NDVI and field observation.

\begin{tabular}{lcc}
\hline Phenophases & $\begin{array}{c}\text { VI-based land surface } \\
\text { phenology }\end{array}$ & Field observation \\
\hline Greenup onset & 124 & 131 \\
Maturity onset & 186 & 187 \\
Senescence onset & 247 & 211 \\
Dormancy onset & 318 & 303 \\
Length of growing season & 194 & 183 \\
${ }^{*}$ In situ phenology observations are collected from Chen and Li [17].
\end{tabular}

derived from satellite and observed on ground are generally similar. However, values corresponding to the satellite onset estimate of senescence and dormancy date lag field-observed values by about $15-35$ days. This may be explained by the field observation protocol adopted in describing phonological dates from maturity to senescence.

To improve accuracy, validation is an essential issue in land surface phenology study over large areas. This requires sufficient comparison between land surface phenology and in situ values, which is challenging because the location of field observation and MODIS pixels may not match [19].

\section{Conflicts of Interests}

The authors have declared that no conflict of interests exists. 


\section{Acknowledgments}

This study was supported by the Key Project of National Natural Science Foundation of China (NSFC, no. 41030101) and the National Natural Science Foundation of China (NSFC, no. 41101115).

\section{References}

[1] A. Hudson Dunn and K. M. de Beurs, "Land surface phenology of North American mountain environments using moderate resolution imaging spectroradiometer data," Remote Sensing of Environment, vol. 115, no. 5, pp. 1220-1233, 2011.

[2] C. G. Rosenzweig, D. J. Casassa, A. Karoly et al., Climate Change 2007: Impacts, Adaptation and Vulnerability: Contribution of Working Group II To the Fourth Assessment Report of the Intergovernmental Panel on Climate Change, vol. 4, Cambridge University Press, 2007.

[3] T. R. Karl, J. M. Melillo, T. C. Peterson, and S. J. Hassol, Global Climate Change Impacts in the United States, Cambridge University Press, 2009.

[4] K. Soudani, G. le Maire, E. Dufrêne et al., "Evaluation of the onset of green-up in temperate deciduous broadleaf forests derived from Moderate Resolution Imaging Spectroradiometer (MODIS) data," Remote Sensing of Environment, vol. 112, no. 5, pp. 2643-2655, 2008.

[5] E. Ivits, M. Cherlet, G. Tóth et al., "Combining satellite derived phenology with climate data for climate change impact assessment," Global and Planetary Change, vol. 88-89, pp. 85-97, 2012.

[6] K. Zhu and M. Wan, A Productive Science-Phenology, Public Science, 1963.

[7] T. H. Sparks and P. D. Carey, "The responses of species to climate over two centuries: an analysis of the Marsham phenological record, 1736-1947," Journal of Ecology, vol. 83, no. 2, pp. 321-329, 1995.

[8] T. Rötzer and F.-M. Chmielewski, "Phenological maps of Europe," Climate Research, vol. 18, pp. 249-257, 2001.

[9] Q. Ge, J. Dai, J. Zheng et al., "Advances in first bloom dates and increased occurrences of yearly second blooms in eastern China since the 1960s: further phenological evidence of climate warming," Ecological Research, vol. 26, no. 4, pp. 713-723, 2011.

[10] I. Chuine, G. Cambon, and P. Comtois, "Scaling phenology from the local to the regional level: advances from speciesspecific phenological models," Global Change Biology, vol. 6, no. 8, pp. 943-952, 2000.

[11] Y. Huang, D. Jiang, D. Zhuang, H. Ren, and Z. Yao, "Filling gaps in vegetation index measurements for crop growth monitoring," African Journal of Agricultural Research, vol. 6, no. 12, pp. 29202930, 2011.

[12] J. N. Hird and G. J. McDermid, "Noise reduction of NDVI time series: an empirical comparison of selected techniques," Remote Sensing of Environment, vol. 113, no. 1, pp. 248-258, 2009.

[13] X. Y. Zhang, M. A. Friedl, C. B. Schaaf et al., "Monitoring vegetation phenology using MODIS," Remote Sensing of Environment, vol. 84, no. 3, pp. 471-475, 2003.

[14] B. C. Reed, J. F. Brown, D. VanderZee, T. R. Loveland, J. W. Merchant, and D. O. Ohlen, "Measuring phenological variability from satellite imagery," Journal of Vegetation Science, vol. 5, no. 5, pp. 703-714, 1994.

[15] N. Delbart, L. Kergoat, T. L. Toan, J. Lhermitte, and G. Picard, "Determination of phenological dates in boreal regions using normalized difference water index," Remote Sensing of Environment, vol. 97, no. 1, pp. 26-38, 2005.

[16] L. Liang, M. D. Schwartz, and S. Fei, "Validating satellite phenology through intensive ground observation and landscape scaling in a mixed seasonal forest," Remote Sensing of Environment, vol. 115, no. 1, pp. 143-157, 2011.

[17] X. Q. Chen and J. Li, "Relationships between Leymus chinensis phenology and meteorological factors in Inner Mongolia grasslands," Acta Ecologica Sinica, vol. 29, no. 10, pp. 5280-5290, 2009.

[18] X. Y. Zhang, M. A. Friedl, and C. B. Schaaf, "Global vegetation phenology from Moderate Resolution Imaging Spectroradiometer (MODIS): evaluation of global patterns and comparison with in situ measurements," Journal of Geophysical Research, vol. 111, no. 4, 2006.

[19] S. Ganguly, M. A. Friedl, B. Tan, X. Zhang, and M. Verma, "Land surface phenology from MODIS: characterization of the collection 5 global land cover dynamics product," Remote Sensing of Environment, vol. 114, no. 8, pp. 1805-1816, 2010. 


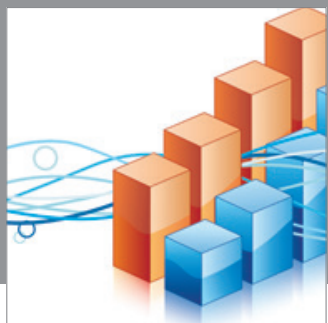

Advances in

Operations Research

mansans

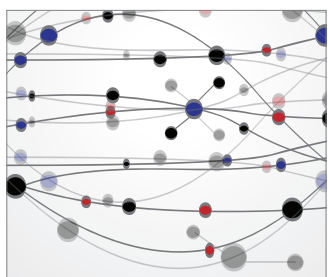

The Scientific World Journal
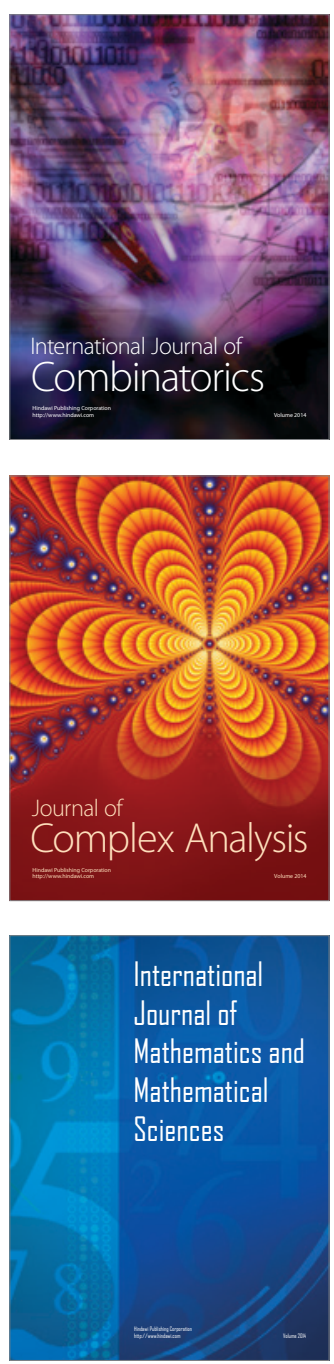
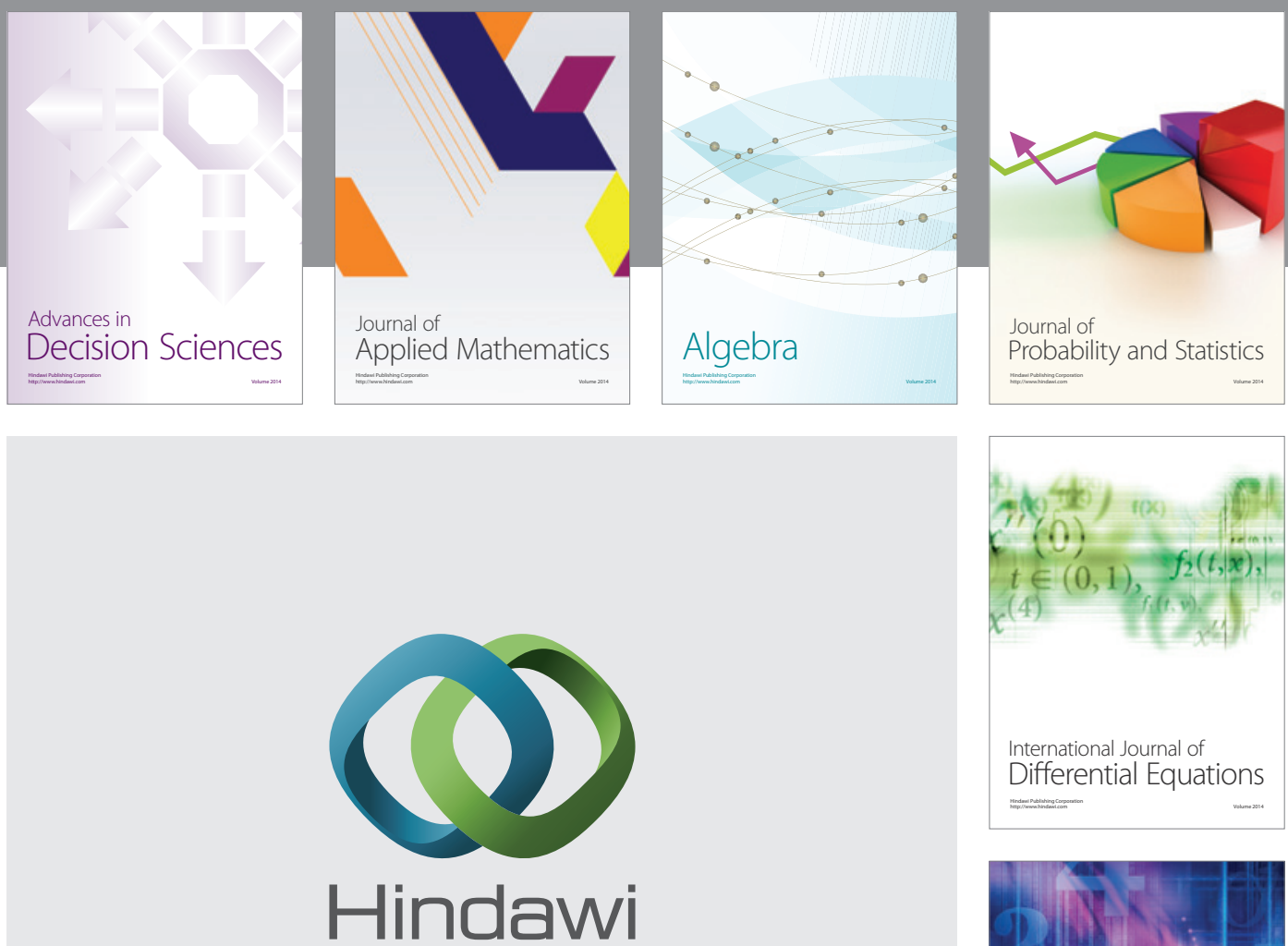

Submit your manuscripts at http://www.hindawi.com
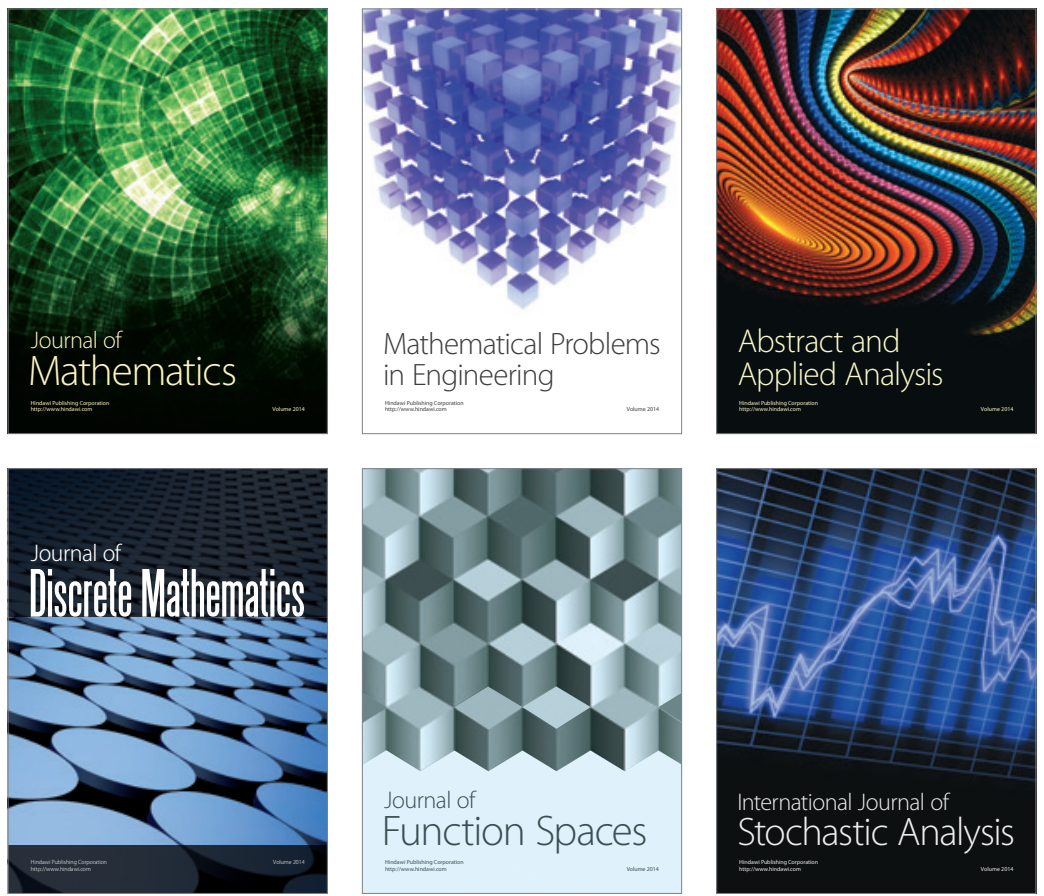

Journal of

Function Spaces

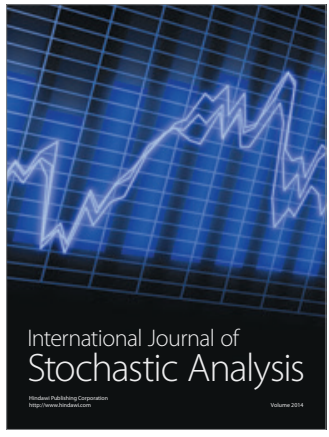

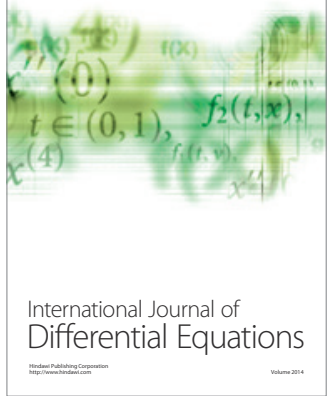
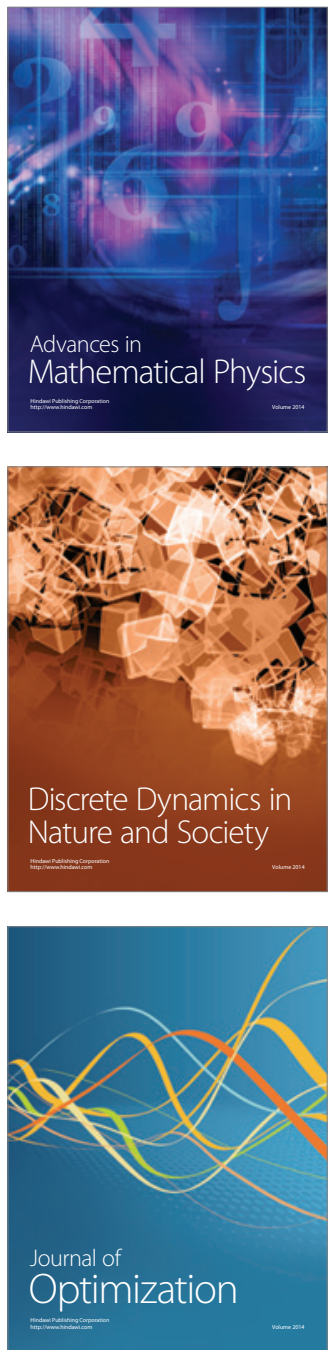